\title{
The short-term skeleto-dental effects of a new spring for the intrusion of maxillary posterior teeth in open bite patients
}

\author{
Riaan Foot ${ }^{1}$, Oyku Dalci ${ }^{1,2^{*}}$, Carmen Gonzales ${ }^{1}$, Nour Eldin Tarraf ${ }^{1}$ and M Ali Darendeliler ${ }^{1}$
}

\begin{abstract}
Background: The technology surrounding temporary skeletal anchorage devices has improved in leaps and bounds. However, no specific auxiliary exists for the intrusion of molars in conjunction with these devices and currently clinicians are forced to make do with available force delivery materials. A new intrusion auxiliary, the Sydney Intrusion Spring (SIS), was designed to facilitate intrusion without frequent need for reactivation or tissue irritation.

Methods: The subjects consisted of 16 adolescent patients ( 12 females and 4 males) with an average age of 13.1 years (range 12.2 to 14.3 years). All patients were in the permanent dentition with an anterior open bite of $\geq 2 \mathrm{~mm}$. Four self-drilling miniscrews were placed into the posterior maxillary buccal alveolar bone. The intrusion appliance consisted of a bonded acrylic appliance and the SIS, activated to produce an initial intrusive force of $500 \mathrm{~g}$. Cone beam computed tomograms were taken after miniscrew placement and at the end of active intrusion. Rendered lateral cephalograms were produced and measurements were taken and compared.

Results: All study objectives were achieved in 4.91 months (range 2.5 to 7.75 months). The mean molar intrusion was $2.9 \pm 0.8 \mathrm{~mm}(P<.001)$, resulting in over bite increase of $3.0 \pm 1.5 \mathrm{~mm}(P<.001)$. The intrusion led to a $2.6^{\circ} \pm 1.3^{\circ}$ $(P<.001)$ clockwise occlusal plane rotation and a $1.2^{\circ} \pm 1.3^{\circ}(P<.01)$ counter-clockwise rotation of the mandible. Dental measurements showed a significant uprighting and elongation of the incisors. There was no significant extrusion of the lower molars.
\end{abstract}

Conclusion: The SIS is an effective appliance for the intrusion of maxillary posterior teeth, in conjunction with miniscrews.

Keywords: Open bite; Molar intrusion; Miniscrew

\section{Background}

Since the start of the modern era of orthodontics, orthodontists have acknowledged anterior open-bite malocclusion to be one of the most difficult malocclusions to successfully treat and maintain.

Literature describes a wide range of clinical features and cephalometric traits descriptive of skeletal anterior open bite that are common to most individuals. However, in any given individual with this type of skeletal dysplasia, several or only a few of the reported characteristics may be observed. A frequent finding however

\footnotetext{
* Correspondence: oyku.dalci@sydney.edu.au

'Discipline of Orthodontics, Faculty of Dentistry, University of Sydney, Sydney, New South Wales 2006, Australia

2Sydney Dental Hospital, 2 Chalmers St, Level 2, Surry Hills, NSW 2010,
} Australia appears to be an inferiorly positioned maxillary process: maxillary posterior vertical excess with concomitant posterior inferiorly tipped palatal plane and an increased posterior and anterior maxillary dentoalveolar height $[1,2]$. This is thought to be due to the excessive vertical maxillary development.

Several conventional treatment methods have traditionally been proposed to treat these patients. Extra-oral traction like high-pull headgear, either to molar tubes, maxillary splint or functional appliance [3,4], with force magnitudes ranging anywhere from 300 to $1,500 \mathrm{gr}$ and application times ranging from 10 to $24 \mathrm{~h}$ per day, have been proposed. Vertical chin cup therapy is another extra-oral approach employed and may also be used alone, with fixed orthodontic appliances or in conjunction with functional

\section{空}


appliances [5] to address vertical control of the mandible during skeletal open bite treatment.

Removable functional orthopaedic appliances [6] have also been described in the literature for the treatment of skeletal anterior open-bite malocclusion. Furthermore, passive posterior bite blocks [7], magnetic bite block appliances [8], the multiloop edgewise archwire technique (MEAW) [9], fixed orthodontic appliances in conjunction with anterior vertical elastics, and extraction treatment have all been suggested as viable treatment modalities for this type of malocclusion. These appliances however all had significant drawbacks and/or side effects.

It has also been proposed that $90 \%$ of the patients with skeletal anterior open dysplasia are best treated by a combination of orthodontic and orthognathic surgical procedures. Most often the maxilla is the principal focus of surgery in skeletal open bite dysplasia, as the vertical development of the nasomaxillary complex is nearly always excessive in these individuals [10]. Surgical treatment however is highly invasive and costly, has inherent risk involved and cannot be undertaken until vertical growth has been completed.

With the advent of orthodontic temporary skeletal anchorage devices (TSADs), orthodontists for the first time have had a reliable source of noncompliance-based stationary anchorage. Umemori et al. [11] were the first to show the possibility of molar intrusion in humans, using skeletal anchorage. Subsequently, several studies [12-16] have shown maxillary molar intrusion, using skeletal anchorage, to be a viable and reliable treatment modality for skeletal anterior open-bite malocclusion.

The orthodontic auxiliaries used to provide the intrusive force component, however, are crude adaptations of existing auxiliaries, including NiTi coil springs, elastomeric thread, or chain and rubber bands. These auxiliaries were not developed for the purpose of molar intrusion in conjunction with skeletal anchorage devices and therefore, although being adequate at accomplishing the task at hand, all have significant limitations and drawbacks. Elastomeric thread or chain requires frequent replacement and reactivation, whilst NiTi coil springs often cause significant tissue irritation and hyperplasia. No mention could be found in the literature, regarding a specifically designed intrusion auxiliary for use in conjunction with skeletal anchorage devices.

Consequently, a specifically designed spring, the Sydney intrusion spring (SIS), was conceived and developed at the University of Sydney. The SIS is a purposely created intrusion auxiliary, designed for maxillary dentoalveolar buccal segment intrusion, to be used in conjunction with skeletal anchorage devices like miniscrews or miniplates. It is designed to produce a continuous active intrusion force with infrequent need for reactivation, be easy to install, reactivate and remove, and be hygienic with minimal tissue irritation.
For the purposes of this study, the null hypothesis assumed that posterior dentoalveolar intrusion using skeletal anchorage and the SIS provided no statistically significant changes in the cephalometric measurements of the subjects studied. The aim of this prospective study is to evaluate the clinical use as well as the dental and skeletal effects of the SIS.

\section{Methods}

The subjects selected for this study consisted of 16 adolescent patients (12 females and 4 males) with an average age of 13.1 years (range 12.2 to 14.3 years).

Ethical approval was obtained from the Human Research Ethics Committee, SSWAHS No. X10-0070\&HREC/10/ $\mathrm{RPAH} / 126$. The criteria for inclusion in the study were the following: patients in the permanent dentition with an anterior open bite between the upper and lower incisors of $2 \mathrm{~mm}$ or greater; adequate incisor display on smiling and at rest; an increased lower anterior facial height; convex profile; no severe maxillary posterior crowding or rotated teeth; no current habits, such as digit sucking or tongue thrust; no previous orthodontic treatment, trauma and no dental or congenital anomalies; good oral hygiene and no periodontal disease.

The intrusion appliance used for this study consisted of three main parts, the SIS, a bonded acrylic maxillary expander and four miniscrews.

The SIS consists of two 0.016-in. diameter beta titanium closing loops containing several helices, laser welded to a $0.017 \times 0.025 \mathrm{in}$. diameter beta titanium frame. The closing loops provide low continuous force production over a large range of activation, whilst the frame provides the required stiffness to resist permanent deformation of the spring during activation and placement (Figure 1a,b).

The bonded acrylic appliance consisted of two shallow acrylic bite blocks with an internal wire frame, covering all teeth to be intruded (premolars and molars) and constructed to produce minimal bite opening. The bite blocks were connected by a 7-mm hyrax expansion (Dentaurum, Ispringen, Germany) screw which was bent to allow sufficient palatal clearance for intrusion. The buccal surface of the bite blocks further incorporated two self-ligating brackets $\left(0.022-i n\right.$. slot, Speed ${ }^{\mathrm{m}}$, Strite Industries, Cambridge, Ontario, Canada) on each side, welded to the internal framework. The brackets were positioned to align with the miniscrews and allow a vertical clearance of $12 \mathrm{~mm}$ between the slot on the miniscrew and the slot on the bracket.

Four self-drilling miniscrews (Aarhus ${ }^{\mathrm{me}}$, Medicon eG, Tuttlingen, Germany; diameter, $1.5 \mathrm{~mm}$; length, $6 \mathrm{~mm}$ distributed by American Orthodontics) were placed into the maxillary buccal alveolar bone through the gingiva. The miniscrews were placed between the upper first and second premolar and the second and first molar on both 

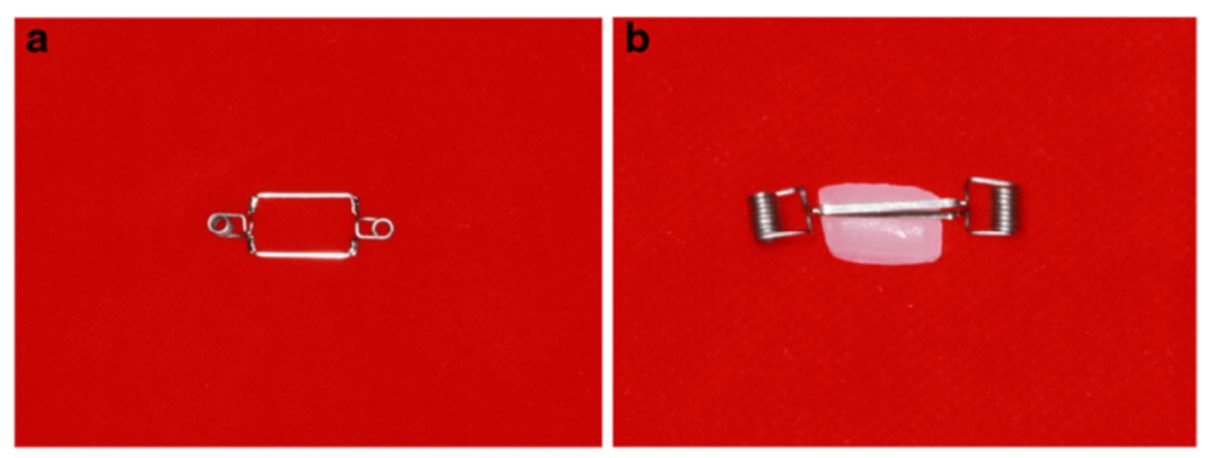

Figure 1 The Sydney intrusion spring (SIS). Side view (a) and top view (b) .

the left and right sides of the maxilla (Figure 2a,b). All miniscrews were placed by a single operator (RF). Alginate impressions were then taken of the upper and lower arches, including the miniscrews.

After laboratory construction, all bonded appliances were checked for fit and cemented using glass ionomer cement. The SIS was then placed bilaterally and activated to produce an initial intrusive force of approximately $500 \mathrm{~g}$ (Figure 3a,b). Loading of the miniscrews was initiated immediately after placement $(<48 \mathrm{~h})$ and continued until sufficient intrusion has been achieved. Rapid maxillary expansion was also prescribed, at a rate of $0.25 \mathrm{~mm}$ per day, until 30\% overexpansion has been achieved. Subjects were seen at 4-week intervals to observe progress, and the springs were reactivated when the force delivery approached $200 \mathrm{~g}$.

Treatment was continued and sufficient intrusion was deemed to be achieved once the over bite, as measured between the upper and lower incisor tips, minus the bite blocks, reached $2 \mathrm{~mm}$ (Figure 4a,b,c,d).

Cone beam computed tomograms (CBCTs) were taken immediately after miniscrew placement at $\mathrm{T} 1$ and at the end of active intrusion, after appliance removal, at T2. The tomograms were acquired using a NewTom 3G (QR, Verona, Italy) with a 12-in. field of view (FOV). The DICOM data obtained from the CBCTs were processed to produce rendered lateral cephalograms, using the Dolphin Imaging system (version 11.0, Dolphin Imaging \& Management Systems, Chatsworth, CA, USA). All cephalograms were digitally traced by one investigator (RF) using the Dolphin software. Twenty-three conventional cephalometric measurements were included, consisting of 12 angular and 11 linear measurements [12-14,16] (Figure 5a,b). To negate any possible contribution from growth, the stable basicranial line (SBL) [17] was also utilized in four linear vertical measurements: SBL-U6, SBL-U1, SBL-PP, and SBL-Gn (Figure 5c). A further measurement from U6 to PP was done by transferring the $\mathrm{PP}$ from the $\mathrm{T} 1$ to $\mathrm{T} 2$ radiograph by regional maxillary superimposition.
An error measurement study was done to evaluate the intra-examiner reliability, 1 month after the initial tracings. In this study, the method error did not exceed $0.3 \mathrm{~mm}$ for the linear variables and $0.4^{\circ}$ for the angular variables.

Statistical analysis of the cephalometric study data was performed using the Statistical Package for the Social Sciences (SPSS, version 17.0, SPSS Inc., Chicago, IL, USA) and was used for descriptive statistical analysis, using paired sample $t$-tests.

\section{Results}

One miniscrew was lost from subject 1 , and this subject was subsequently removed from the study. The final subject population therefore consisted of 11 females and 4 males with an average pretreatment open bite of $2.6 \mathrm{~mm}$ (range 2.1 to $6 \mathrm{~mm}$ ). The study objectives were achieved in all patients, and the average intrusion time was 4.91 months (range 2.5 to 7.75 months).

The data from the pretreatment and post intrusion lateral cephalograms, local superimpositions as well as results of the paired $t$-test are summarized in Table 1 . Statistically significant changes were observed in several key cephalometric parameters.

The main study objective, posterior dental intrusion, was shown to be effectively achieved, as is reflected by the parameters measuring this outcome. The U6-PP decreased by $2.9 \pm 0.8 \mathrm{~mm}(P<.001)$, SBL-U6 reduced by $3.2 \pm 0.6 \mathrm{~mm}(P<.001)$ and local superimposition showed a reduction of $2.7 \pm 0.7 \mathrm{~mm}(P<.001)$ to the maxillary reference line. This translated to an average over bite increase of $3.0 \mathrm{~mm} \pm 1.5 \mathrm{~mm}(P<.001)$. This observed dental intrusion proceeded at an average rate of $0.59 \mathrm{~mm} / \mathrm{month}$.

There was significant uprighting and elongation of the upper and lower incisors. The U1/SN was statistically significantly decreased by $4.5^{\circ} \pm 3.3^{\circ} \quad(P<.001)$ and the U1-PP measurement increased by $0.9 \pm 0.6 \mathrm{~mm}$ $(P<.001)$. The lower incisors uprighted by $6.6^{\circ} \pm 3.8^{\circ}$ $(P<.001)$ and showed an average elongation of $1.4 \pm$ $0.8 \mathrm{~mm}(P<.001)$ to the mandibular plane. These 

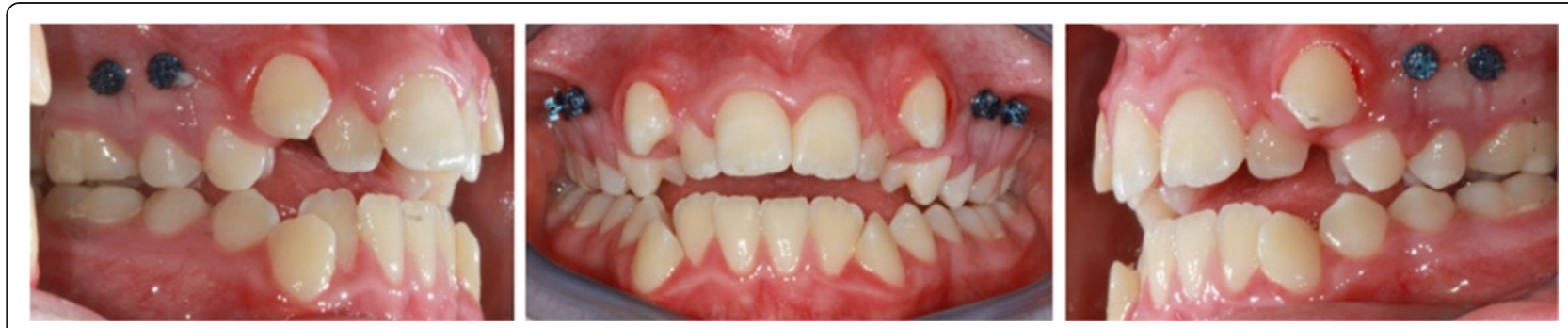

Figure 2 Miniscrew placement.

changes led to an average increase in the interincisal angle of $12.2^{\circ} \pm 5.1^{\circ}(P<.001)$.

The posterior dental intrusion caused a clockwise rotation of the upper occlusal plane, leading to an increase in angulation of Occ $\mathrm{Pl} / \mathrm{SN}$ of $2.6^{\circ} \pm 1.3^{\circ}(P<.001)$. The intrusion also caused a counter clockwise autorotation of the mandible. This lead to decrease in SN/MP of $1.2^{\circ} \pm 1.3^{\circ}(P<.01)$, a decrease of $0.9^{\circ} \pm 1.2^{\circ}(P<.05)$ in FMA and a $1.01 \pm 1.44 \mathrm{~mm}(P<.05)$ decrease in SBL-Gn. These changes translated to a decrease in lower anterior facial height of $0.9 \pm 1 . \mathrm{mm}(P<.01)$.

There was no significant increase in the measurement of the lower molars to the mandibular plane or SBL to the palatal plane. Midfacial skeletal parameters also remained stable.

\section{Discussion}

The literature suggests an inferiorly positioned maxillary process; maxillary posterior vertical excess, with concomitant posterior, inferiorly tipped palatal plane; and an increased posterior and anterior maxillary dentoalveolar height, to be major and frequent characteristics of individuals with a skeletal open-bite malocclusion $[1,2]$. The treatment objective for these patients should therefore be intrusion of the maxillary posterior teeth, to address the morphological discrepancies present with this malocclusion and to improve facial aesthetics.

The intrusion of posterior teeth, using skeletal anchorage was first shown to be possible by Southard et al. [18] in mongrel dogs, using osseointegrated implants. With the introduction of miniscrews Ohmae et al. [19] subsequently demonstrated the possibility of using miniscrews for the intrusion of mandibular third premolar teeth in beagle dogs. Following the report on molar intrusion in human subjects by Umemori et al. [11], there has been several studies that have shown molar intrusion, using TSAD, to be a viable treatment modality [12-16].

However, no firm evidence exists in the literature regarding the optimal force levels for maxillary dentoalveolar intrusion. The proponents of extra-oral traction, in the form of headgear, advocate relatively high-force magnitudes ranging anywhere from 300 to $1,500 \mathrm{~g}$ of force. Most however use forces in the range of 400 to $600 \mathrm{~g}$. In terms of traditional intra-oral tooth borne mechanics, Burstone [20] suggested $20 \mathrm{~g}$ of intrusive force for incisors and $50 \mathrm{~g}$ for canines, whilst Proffit [21] advocates 10 to $20 \mathrm{~g}$ of continuous intrusive force. Kalra et al. [22] applied $90 \mathrm{~g}$ of force to intrude molars in children compared to Melson and Fiorelli [23] who suggested $50 \mathrm{~g}$ of force for molar intrusion in adults. With the advent of skeletal anchorage, force systems could be altered and increased without concern for unwanted side effects in the reactive unit and Büchter [24] found miniscrews to remain clinically stable at force levels up to 900 g. Using skeletal anchorage, the suggested intrusive force level for single maxillary molars, from literature, appears to be 100 to $200 \mathrm{~g}$ [25]. Kato and Kato however found $100 \mathrm{~g}$ of force to be insufficient
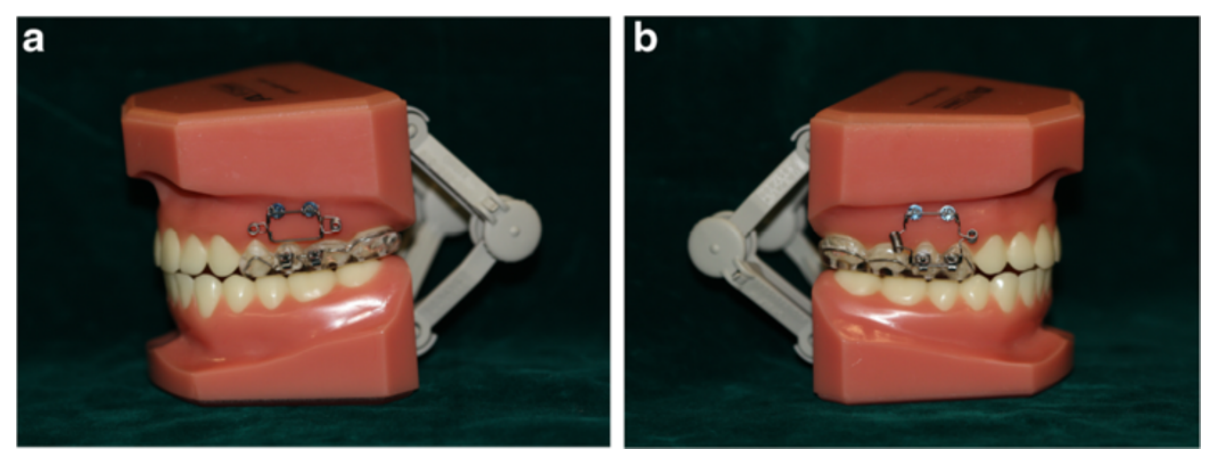

Figure 3 SIS activation. (a) Inactive. (b) Activated. 


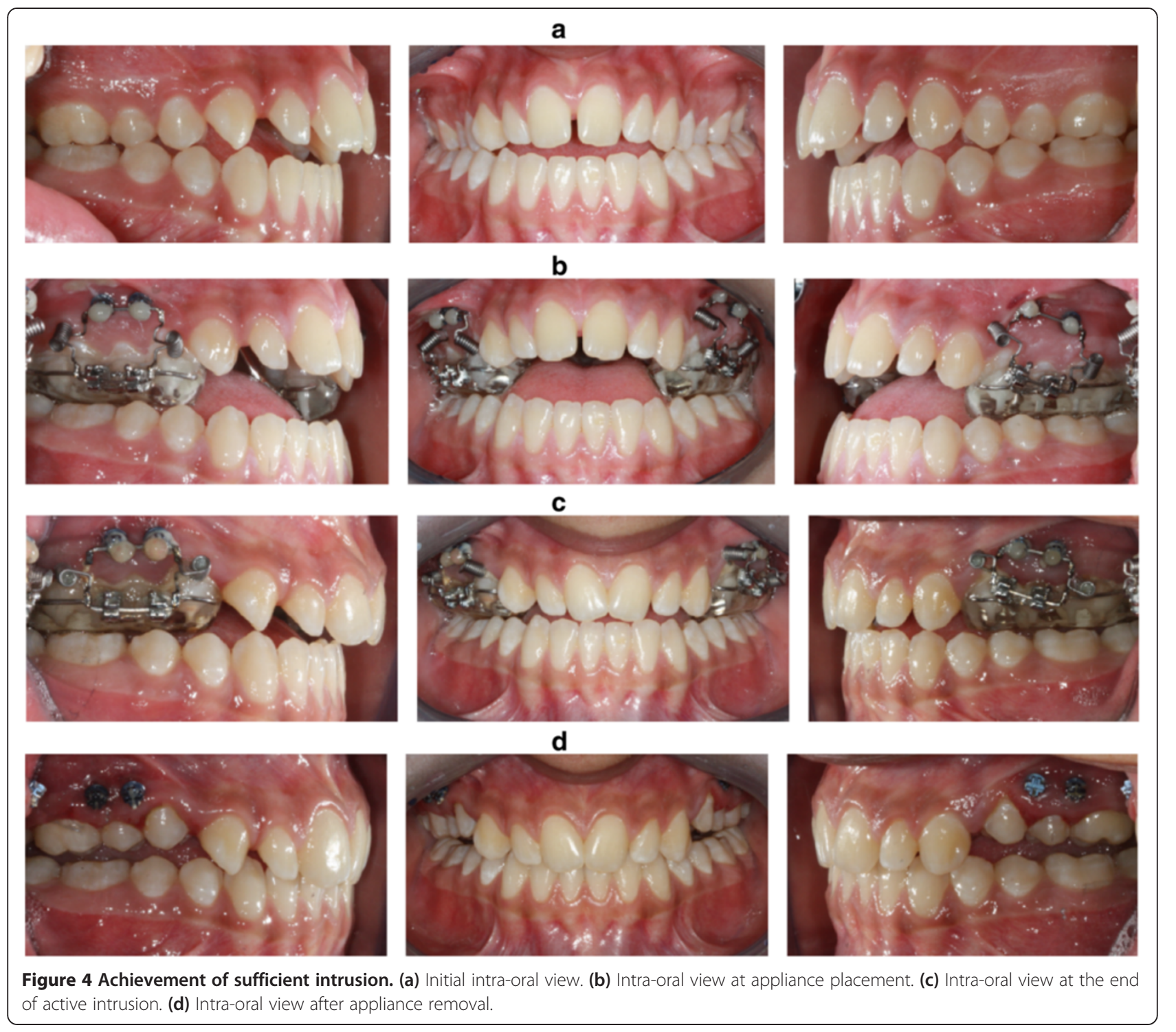

for en masse molar intrusion, but smooth progressive intrusion was achieved when the force levels where increased to $300 \mathrm{~g}$ per side [26]. The literature therefore seems to suggest optimal force levels of 200$500 \mathrm{~g}$ for en masse molar intrusion using skeletal anchorage [12-16].

Consequently the SIS, a purposely designed intrusion auxiliary, was developed to produce clinically significant, efficient en masse intrusion of posterior teeth. Laboratory tests suggest that the SIS is able to deliver these suggested force levels of 500 to $200 \mathrm{~g}$ in a curvilinear fashion from an activation of $5.5 \mathrm{~mm}$ down to $0.8 \mathrm{~mm}$.

The present study is the first to investigate the treatment of skeletal anterior open-bite malocclusion, through molar intrusion with TSADs, in an adolescent sample group. Our results, which indicate an average of $2.9 \mathrm{~mm}$ molar intrusion and $3.0 \mathrm{~mm}$ increase in overbite, however compares favourably to the results of conventional open bite treatment in adolescents. A major shortcoming of our study is that it does not include an untreated control group. The main aim of this paper was to report on the preliminary findings of a newly designed molar intrusion appliance and future long-term studies should include an untreated control group. The SBL (Figure 5c) was utilised to negate any possible contribution from growth, and a further vertical measurement from U6 to PP was done by transferring the PP from the $\mathrm{T} 1$ to $\mathrm{T} 2$ radiograph by regional maxillary superimposition as well.

Firouz et al. [27] investigated the effect of high-pull headgear in 12 patients with an anterior open bite of at least $2 \mathrm{~mm}$. The headgear was worn for $12 \mathrm{~h}$ per day for 6 months and produced an average of $0.54 \mathrm{~mm}$ intrusion of the maxillary molars. Orton et al. [28] 

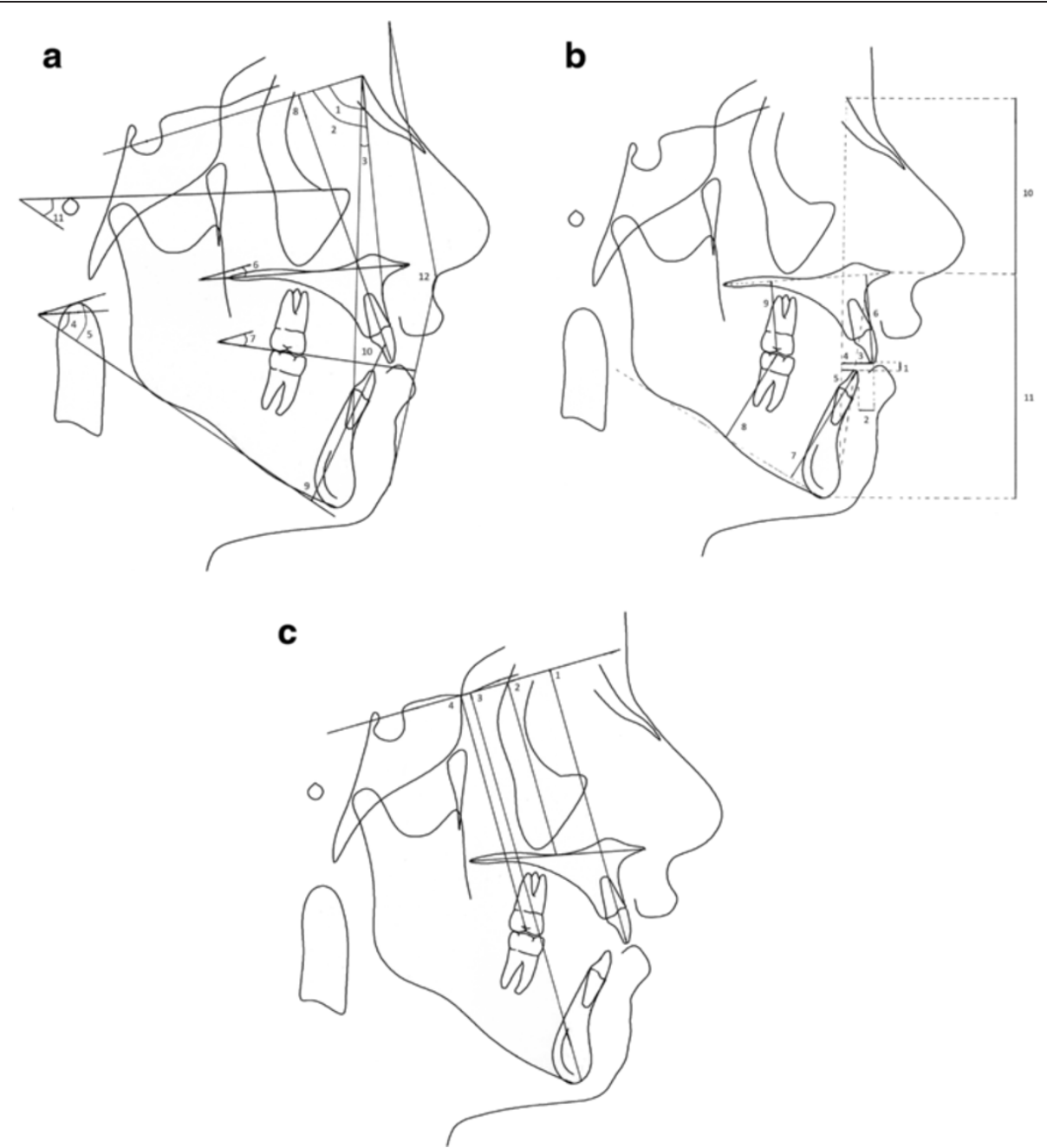

Figure 5 The cephalometric measurements. (a) Angular measurements: 1, SNA angle; 2, SNB angle; 3, ANB angle; 4, mandibular plane to palatal plane angle (PP/MP); 5, sella-nasion line to mandibular plane angle (SN/MP); 6, sella-nasion line to palatal plane angle (SN/PP); 7, occlusal plane to sella-nasion line angle (Occ/SN); 8, maxillary central incisor to sella-nasion line angle (U1/SN); 9, mandibular central incisor goniongnathion line angle (L1/GoGn); 10, interincisal angle (U1/L1); 11, mandibular plane to Frankfurt horizontal (MP/FH); 12, facial convexity (G'Sn'Po'). (b) Linear measurements: 1, over bite; 2, overjet; 3, maxillary central incisor protrusion (U1-Apo); 4, maxillary incisor to nasion-pogonion line (U1-NPo); 5, mandibular central incisor to mandibular plane (L1-MP); 8, mandibular fist molar to mandibular plane (L6-MP); 9, maxillary first molar to palatal plane (U6-PP); 10, upper anterior facial height (UAFH); 11, lower anterior facial height (LAFH). (c) SBL measurements: 1, measurement to maxillary central incisor tip (SBL-U1); 2, measurement to palatal plane (SBL-PP); 3, measurement to maxillary first molar occlusal surface (SBL-U6); 4, measurement to gnathion (SBL-Gn).

demonstrated $0.72 \mathrm{~mm}$ of molar intrusion when using a maxillary intrusion splint and vertical pull headgear with $500 \mathrm{~g}$ of force per side, for $14 \mathrm{~h}$ per day. Recently Abudallatif and Keles [29] described the use of an acrylic cap splint expander and occipital headgear to cause intrusion of the maxillary posterior teeth and a clockwise moment on the maxillary dentoalveolar complex. The headgear was activated to produce a force of $500 \mathrm{~g}$ per side and was worn for 14 to $16 \mathrm{~h}$ per day for 6 months. Results suggested a clockwise rotation of the maxillary dentition, reduction in mandibular plane angle; maxillary molar intrusion of $2.81 \mathrm{~mm}$ and an over bite increase of $3.75 \mathrm{~mm}$.
A study by Kiliaridis et al. [30] comparing passive posterior bite blocks to posterior repelling splints suggest that passive blocks are able to produce a vertical over bite correction of 1.5 to $3.0 \mathrm{~mm}$ in younger individuals, but that the main improvement seems to occur in the first weeks, followed by a 'plateau' period. No figure was given for the amount of molar intrusion achieved.

Investigation into a fixed magnetic appliance, producing an intrusive force of $1,080 \mathrm{~g}$ to the upper and lower posterior dentition, by Kalra et al. [22] found an average of $1.6 \mathrm{~mm}$ maxillary molar intrusion, $3.8 \mathrm{~mm}$ increase in over bite and a mandibular plane angle decrease of $1.3^{\circ}$ after 4 months of treatment. However, a 4 month 
Table 1 Summarized cephalometric changes from T1 to T2

\begin{tabular}{|c|c|c|c|c|c|c|c|c|}
\hline \multirow[t]{2}{*}{ Cephalometric variables } & \multicolumn{2}{|l|}{$\mathrm{T1}$} & \multicolumn{2}{|l|}{$\mathrm{T2}$} & \multicolumn{2}{|c|}{ Difference } & \multirow[t]{2}{*}{$P$ value } & \multirow[t]{2}{*}{ Significance } \\
\hline & Mean & SD & Mean & SD & Mean & SD & & \\
\hline ANB $\left(^{\circ}\right)$ & 4.8 & 2.9 & 4.5 & 2.8 & -0.4 & 0.9 & .139 & NS \\
\hline SNA $\left(^{\circ}\right)$ & 81.6 & 5.7 & 81.8 & 5.8 & 0.2 & 0.5 & .183 & NS \\
\hline SNB $\left(^{\circ}\right)$ & 76.8 & 4.8 & 77.4 & 5.4 & 0.6 & 1.0 & .054 & NS \\
\hline $\mathrm{PP} / \mathrm{MP}\left({ }^{\circ}\right)$ & 31.8 & 3.8 & 30.7 & 4.3 & -1.0 & 1.3 & .009 & $* *$ \\
\hline U1-SN $\left(^{\circ}\right)$ & 107.3 & 8.5 & 102.8 & 8.3 & -4.5 & 3.3 & .000 & $* * *$ \\
\hline Occ plane to SN $\left(^{\circ}\right)$ & 17.1 & 4.4 & 19.6 & 4.7 & 2.6 & 1.3 & .000 & $* * *$ \\
\hline SN-MP $\left(^{\circ}\right)$ & 36.1 & 4.9 & 34.9 & 5.3 & -1.2 & 1.3 & .002 & $* *$ \\
\hline SN/PP $\left({ }^{\circ}\right)$ & 7.1 & 2.7 & 7.0 & 2.6 & -0.1 & 0.6 & .647 & NS \\
\hline L1-GoGn ( $\left.{ }^{\circ}\right)$ & 97.5 & 8.7 & 91.0 & 7.9 & -6.6 & 3.8 & .000 & $* * *$ \\
\hline Interincisal angle $\left({ }^{\circ}\right)$ & 119.5 & 12.2 & 131.6 & 11.6 & 12.2 & 5.1 & .000 & $* * *$ \\
\hline$\left(\mathrm{G}^{\prime} \mathrm{Sn}^{\prime} \mathrm{Po}\right)\left({ }^{\circ}\right)$ & 160.5 & 5.5 & 160.1 & 5.8 & -0.4 & 1.4 & .256 & NS \\
\hline FMA (MP/FH) $\left(^{\circ}\right)$ & 27.8 & 3.5 & 26.9 & 3.6 & -0.9 & 1.2 & .015 & * \\
\hline Over bite (mm) & -2.2 & 1.7 & 0.8 & 1.1 & 3.0 & 1.5 & .000 & $* * *$ \\
\hline Overjet (mm) & 4.5 & 2.3 & 4.4 & 1.8 & -0.1 & 1.2 & .900 & NS \\
\hline U1-Apo (mm) & 8.6 & 3.1 & 7.4 & 3.1 & -1.2 & 0.9 & .000 & $* * *$ \\
\hline U1-NPo (mm) & 11.1 & 4.3 & 9.6 & 4.0 & -1.5 & 1.2 & .000 & $* * *$ \\
\hline U1-PP (mm) & 25.6 & 2.3 & 26.5 & 2.4 & 0.9 & 0.6 & .000 & $* * *$ \\
\hline L1-APo (mm) & 4.1 & 3.3 & 3.0 & 3.2 & -1.2 & 0.9 & .000 & $* * *$ \\
\hline L1-MP (mm) & 34.7 & 2.8 & 36.1 & 2.7 & 1.4 & 0.8 & .000 & $* * *$ \\
\hline L6-MP (mm) & 27.9 & 2.9 & 28.0 & 2.9 & 0.1 & 0.4 & .201 & NS \\
\hline U6-PP (mm) & 20.6 & 2.3 & 17.7 & 2.4 & -2.9 & 0.8 & .000 & $* * *$ \\
\hline LAFH (mm) & 61.8 & 4.3 & 60.9 & 4.6 & -0.9 & 1.1 & .009 & $* *$ \\
\hline UAFH (mm) & 48.6 & 3.4 & 48.6 & 3.3 & 0.0 & 0.7 & .908 & NS \\
\hline U6-Mx reference plane $(\mathrm{mm})$ & 20.5 & 2.4 & 17.8 & 2.3 & -2.7 & 0.7 & .000 & $* * *$ \\
\hline SBL-U6 & 69.9 & 4.6 & 66.7 & 4.8 & -3.2 & 0.6 & .000 & $* * *$ \\
\hline SBL-U1 & 82.3 & 5.7 & 83.1 & 5.6 & 0.9 & 0.8 & .000 & $* * *$ \\
\hline SBL-PP & 52.0 & 4.0 & 52.4 & 3.8 & 0.4 & 0.4 & .000 & $* * *$ \\
\hline SBL-Gn & 110.6 & 7.5 & 109.6 & 7.5 & -1.0 & 1.4 & .016 & * \\
\hline
\end{tabular}

U1: upper incisor; L1: lower incisor, U6: upper first molar; L6: lower first molar, SBL: stable basicranial line.

${ }^{*} \mathrm{p}<0.05,{ }^{* *} \mathrm{p}<0.01,{ }^{* * *} \mathrm{p}<0.001$.

follow up period saw $1.8 \mathrm{~mm}$ of eruption of the maxillary molars. Meral and Yüksel [8] studying the MAD IV appliance, a removable appliance consisting of anterior attracting and posterior repelling magnets, producing a reciprocal force of $300 \mathrm{~g}$, found no significant maxillary molar movement, but $0.75 \mathrm{~mm}$ of mandibular molar intrusion with the use of this appliance.

The literature on maxillary molar intrusion using TSADs consists primarily of individual case reports and the patients were all adults with long standing anterior open-bite malocclusion, many of whom had refused conventional combined orthodontic-orthognathic surgical treatment.

Kuroda et al. [14] in their prospective study of 10 adult female subjects (mean age 21.6 years) with an anterior open-bite malocclusion of $5.2 \mathrm{~mm}$ on average $( \pm 1.8 \mathrm{~mm})$, by means of either SAS miniplates or titanium miniscrews; showed an average of $3.6 \mathrm{~mm}$ of molar intrusion, $6.8 \mathrm{~mm}$ over bite increase, $3.3^{\circ}$ reduction in mandibular plane and no elongation of the incisors. These results were achieved in 7 months of active intrusion.

A subsequent study on molar intrusion by Erverdi et al. [13] evaluated the maxillary posterior dentoalveolar segment intrusion in 11 anterior open bite subjects with a mean age of 19.5 years. For this study the authors used two $9 \mathrm{~mm}$ NiTi coil springs on each side, increasing the intrusive force to $400 \mathrm{~g}$ per side. Results suggest a mean molar intrusion of $3.6 \mathrm{~mm}$, an over bite increase of $5.1 \mathrm{~mm}$ and $3.0^{\circ}$ reduction in facial convexity. No significant changes were observed in the vertical or angular incisor position. The average treatment time was 9.6 months. 
Xun et al. [16] employed both maxillary palatal and mandibular buccal miniscrews to evaluate the posterior dentoalveolar intrusion in 12 subjects (mean age 18.7 years) with a mean pretreatment open bite of $2.2 \mathrm{~mm}$. Results suggest that the maxillary first molars were intruded on average $1.8 \mathrm{~mm}$, mandibular molars $1.2 \mathrm{~mm}$, mandibular plane angle decreased by $2.3^{\circ}$ and the over bite increased by $4.2 \mathrm{~mm}$ in 6.8 months. They further report $1.3 \mathrm{~mm}$ extrusion of both the upper and lower incisors, $5.0^{\circ}$ retroclination of the upper and $1.4^{\circ}$ of the lower incisors and a $4.4^{\circ}$ increase in the occlusal plane to $\mathrm{SN}$.

Data from the current study suggests intrusion of $2.9 \mathrm{~mm}$ at the maxillary first molars, an over bite increase of $3.0 \mathrm{~mm}$, mandibular plane decrease of $1.2^{\circ}$ and an occlusal plane increase of $2.6^{\circ}$. These results compare favourably to those found by several other studies $[12,15,16]$ but is less than that found by Erverdi et al. [13] and Kuroda et al. [14] The greater intrusion found by these studies might be explained by the fact that the their subject group started with larger pretreatment open bites, Kuroda et al. [14] mean pretreatment open bite: $5.2 \mathrm{~mm}$, and therefore required significantly greater intrusion than our sample, who had an average pretreatment open bite of $2.6 \mathrm{~mm}$.

The significant elongation and uprighting of the upper and lower incisors, with the upper incisors extruding by $0.9 \mathrm{~mm}$ and retroclining by $4.5^{\circ}$, whilst the lower incisors extruded by $1.4 \mathrm{~mm}$ and uprighted by $6.6^{\circ}$, are in concurrence with the results found by Erverdi et al. [12] and Xun et al. [16].

The active intrusion time in the present study is comparable to that of Sherwood et al. [15] and Erverdi et al. [12], but with greater dentoalveolar intrusion achieved and significantly shorter than several other studies $[13,14,16]$.

Due to the fact that our subject population consist of growing individuals, the contribution of relative intrusion, through vertical maxillary growth, to the total intrusion achieved could not be disregarded. Therefore, additional measurement using regional superimposition to transfer the maxillary plane was done. Measurement from SBL to the palatal plane was also done to further verify the prior. These parameters indicated that there had been virtually no vertical maxillary growth during the treatment intervention period. Relative intrusion has therefore not significantly contributed to the amount of intrusion achieved, as measured to the palatal plane. This may have attributed to the relatively brief duration of the treatment intervention.

The presence of the SIS was well tolerated by all subjects. Subjects also reported little difficulty in adaption and maintenance of the appliance. Subjective clinical observation suggests that the SIS resulted in little or no tissue irritation and no gingival overgrowth, even in the presence of poor oral hygiene. One possible side effect of intrusion using buccal miniscrews could be the roots of the intruding teeth impinging on the miniscrews after intrusion; however, this was not observed in this study, as the miniscrews were placed with enough clearance in the alveolar bone.

Although several previous studies employed titanium miniplate anchorage, self-drilling orthodontic miniscrews with a diameter of 1.5 and $6 \mathrm{~mm}$ in length were used in the current study. We believe that these devices are reliable and effective sources of anchorage for molar intrusion. Furthermore, they offer a simple insertion and explanation technique, are relatively affordable and require very little instrumentation for placement and removal. Compared to miniplates, this treatment generally requires a very atraumatic surgical procedure with greater patient comfort and better postoperative sequelae.

Interestingly, several studies suggest increased failure rates of miniscrews in younger adolescent patients. Others further suggest higher than average failure rates in individuals with a hyperdivergent open bite facial pattern, increased mandibular plane angle, high Frankfurt horizontal plane and low upper gonial angles. These factors have mainly been related to a decreased cortical bone thickness in younger patients and individuals with a hyperdivergent skeletal open bite facial pattern [31,32]. These findings however have not been supported by our current data, with only 1 out of the 64 miniscrews placed during the study, failing.

Molar intrusion using skeletal anchorage is a relatively new treatment modality; hence, very limited literature exists on the stability of the intrusion results achieved. Sugawara et al. [33] were the first to report on treatment stability, suggesting a relapse rate of $30 \%$ for mandibular molar intrusion 1 year after treatment.

Baek et al. [34] recently were the first to publish an investigation on the long-term stability of maxillary posterior dentoalveolar segment intrusion using skeletal anchorage devices. Their report describes the post treatment changes in nine adult patients (average age 23.7 years), 3 years after treatment. On average, the maxillary molars were intruded by $2.39 \mathrm{~mm}$ and experienced eruption of $0.45 \mathrm{~mm}$ during the 3 -year follow-up period. This equated to a relapse rate of $22.9 \%$, with authors further reporting that $80 \%$ of the total relapse occurred in the first year of retention. In parallel with this, the over bite increased by a mean of $5.56 \mathrm{~mm}$ during treatment but only relapsed by $1.2 \mathrm{~mm}$ in 3 years.

\section{Conclusions}

The SIS, a purposely designed intrusion auxiliary, is an effective appliance for the intrusion of maxillary posterior teeth used in conjunction with miniscrew TSADs. 
The appliance is able to achieve clinically significant intrusion over a large range of activation, with minimal maintenance and requirement for reactivation.

The presence of the appliance is well tolerated by patients and resulted in minimal tissue irritation and no gingival overgrowth.

\section{Competing interests}

The authors declare that they have no competing interests.

\section{Authors' contributions}

RF has undertaken the clinical part of the study, did the statistical analysis and wrote the manuscript. OD has contributed to the design of the study and has revised the manuscript for submission. CG has contributed to the design of the study. NET has contributed to the design of the appliance. MAD came up with the appliance design and contributed to the conception of the study. All authors read and approved the final manuscript.

\section{Acknowledgements}

We wish to thank the following: Mr Chaiy Rungsiyakull at the School of Aerospace, Mechanical and Mechatronic Engineering, University of Sydney for the laboratory testing of several incarnations of the SIS; Dr Peter Petocz, Department of Mathematical Sciences, Macquarie University for his assistance with the statistical analysis; American Orthodontics; Dentaurum and Colgate for their generosity in the donation of the materials and equipment used during the project; and the management and staff of the Sydney Dental Hospital for their support

Received: 1 April 2014 Accepted: 27 August 2014

Published online: 25 September 2014

\section{References}

1. Fields HW, Proffit WR, Nixon WL, Phillips C, Stanek E. Facial pattern differences in long-faced children and adults. Am J Orthod. 1984; 85(3):217-23.

2. Vaden J, Pearson E. Diagnosis of the vertical dimension. Semin Orthod. 2002; 8(3):120-29.

3. Joffe L, Jacobson A. The maxillary orthopedic splint. Am J Orthod. 1979; 75(1):54-69.

4. Hagg U, Du X, Rabie ABM. Initial and late treatment effects of headgear-Herbst appliance with mandibular step-by-step advancement. Am J Orthod Dentofacial Orthop. 2002; 122(5):477-85.

5. Iscan HN, Dinçer M, Gültan A, Meral O, Taner-Sarisoy L. Effects of vertical chincap therapy on the mandibular morphology in open-bite patients. Am J Orthod Dentofacial Orthop. 2002; 122(5):506-11.

6. Weinbach JR, Smith RJ. Cephalometric changes during treatment with the open bite bionator. Am J Orthod Dentofacial Orthop. 1992; 101(4):367-74.

7. McNamara JA. An experimental study of increased vertical dimension in the growing face. Am J Orthod. 1977; 71(4):382-95.

8. Meral O, Yüksel S. Skeletal and dental effects during observation and treatment with a magnetic device. Angle Orthod. 2003; 73(6):716-22.

9. Kim YH, Han UK, Lim DD, Serraon MLP. Stability of anterior openbite correction with multiloop edgewise archwire therapy: a cephalometric follow-up study. Am J Orthod Dentofacial Orthop. 2000; 118(1):43-54.

10. Epker BN, Fish LC. Surgical-orthodontic correction of open-bite deformity. Am J Orthod. 1977: 71(3):278-99.

11. Umemori M, Sugawara J, Mitani H, Nagasaka H, Kawamura H. Skeletal anchorage system for open bite correction. Am J Orthod Dentofacial Orthop. 1998; 115:166-74.

12. Erverdi N, Keles A, Nanda R. The use of skeletal anchorage in open bite treatment: a cephalometric evaluation. Angle Orthod. 2004; 74:381-90.

13. Erverdi N, Usumez S, Solak A, Koldas T. Noncompliance open-bite treatment with zygomatic anchorage. Angle Orthod. 2007; 77(6):986-90.

14. Kuroda S, Sakai Y, Tamamura N, Deguchi T, Takano-Yamamoto T. Treatment of severe anterior open bite with skeletal anchorage in adults: comparison with orthognathic surgery outcomes. Am J Orthod Dentofacial Orthop. 2007; 132(5):559-605.

15. Sherwood K, Burch J, Thompson W. Closing anterior open bites by intruding molars with titanium miniplate anchorage. Am J Orthod Dentofacial Orthop. 2002; 122:593-600.
16. Xun C, Zeng $X$, Wang $X$. Microscrew anchorage in skeletal anterior open-bite treatment. Angle Orthod. 2007; 77(1):47-55.

17. Baccetti T, Franchi L, McNamara JA. Treatment and posttreatment craniofacial changes after rapid maxillary expansion and facemask therapy. Am J Orthod Dentofacial Orthop. 2000; 118(4):404-13.

18. Southard T, Buckley M, Spivey J, Krizan K, Casko J. Intrusion anchorage potential of teeth versus rigid endosseous implants: a clinical and radiographic evaluation. Am J Orthod Dentofacial Orthop. 1995; 107(2):115-20.

19. Ohmae M, Saito S, Morohashi T, Seki K, Qu H, Kanomi R, Yamasaki Kl, Okano T, Yamada S, Shibasaki Y. A clinical and histological evaluation of titanium mini-implants as anchors for orthodontic intrusion in the beagle dog. Am J Orthod Dentofacial Orthop. 2001; 119:489-97.

20. Burstone CR. Deep overbite correction by intrusion. Am J Orthod. 1977; 72(1):1-22.

21. Proffit W, Fields H, Sarver D. Contemporary Orthodontics. 4th ed. Elsevier Mosby; 2007.

22. Kalra V, Orth D, Burstone $C J$, Nanda R. Effects of a fixed magnetic appliance on the dentofacial complex. Am J Orthod Dentofacial Orthop. 1989; 95(6):467-78.

23. Melson B, Fiorelli G. Upper molar intrusion. J Clin Orthod. 1996; 30(2):91-6.

24. Büchter A, Wiechmann D, Koerdt S, Wiesmann HP, Piffko J, Meyer U. Load-related implant reaction of mini-implants used for orthodontic anchorage. (Belastungsbedingte Reaktionen von Mini-Implantaten, welche für orthodontische Verankerungen verwendet werden). Clin Implant Dent Rel Res. 2005; 16(4):473-79.

25. Kravitz N, Kusnoto B, Tsay T, Hohlt W. The use of temporary anchorage devices for molar intrusion. J Am Dent Assoc. 2007; 138:56-64.

26. Kato $S$, Kato M. Intrusion of molars with implants as anchorage: a report of two cases. Clin Implant Dent Rel Res. 2006; 8(2):100-06.

27. Firouz M, Zernik J, Nanda R. Dental and orthopedic effects of high-pull headgear in treatment of Class II, division 1 malocclusion. Am J Orthod Dentofacial Orthop. 1992; 102(3):197-205.

28. Orton HS, Slattery DA, Orton S. Treatment of severe 'gummy' Class II division malocclusion using the maxillary intrusion splint. Eur J Orthod. 1992; 14(3):216-23.

29. Abdullatif $H$, Keles A. A new method for correction of anterior open bite. World J Orthod. 2001; 2:232-43.

30. Kiliaridis S, Egermark I, Thilander B. Anterior open bite treatment with magnets. Eur J Orthod. 1990; 12:447-57.

31. Lee S, Ahn S, Lee J, Kim S, Kim T. Survival analysis of orthodontic miniimplants. Am J Orthod Dentofacial Orthop. 2010; 137(2):194-99.

32. Moon C-H, Park H-K, Nam J-S, Im J-S, Baek S-H. Relationship between vertical skeletal pattern and success rate of orthodontic mini-implants. Am J Orthod Dentofacial Orthop. 2010; 138(1):51-7.

33. Sugawara J, Baik U, Umemori M, Takahashi I, Nagasaka H, Kawamura H Mitani H. Treatment and posttreatment changes following intrusion of mandibular molars with application of a skeletal anchorage system (SAS) for open bite correction. Int J Adult Orthod Orthognath Surg. 2002; 17:243-53.

34. Baek M-S, Choi Y-J, Yu H-S, Kwak J, Park YC. Long-term stability of anterior open-bite treatment by intrusion of maxillary posterior teeth. Am J Orthod Dentofacial Orthop. 2010; 138(4):396.e1-e9.

\section{doi:10.1186/s40510-014-0056-7}

Cite this article as: Foot et al.: The short-term skeleto-dental effects of a new spring for the intrusion of maxillary posterior teeth in open bite patients. Progress in Orthodontics 2014 15:56. 